\title{
Study on Architectural Decoration Engineering Technology to Adapt to the Economic Development of the Pearl River Aimin Wei
}

Guangzhou Urban Construction Vocational College, Guangzhou 510925, Guangdong Province, China

\begin{abstract}
Economic development, education will rank the first position. Higher vocational colleges talent training should meet the needs of regional economic development, the Pearl River Delta region have significantly different development characteristics with other regions. The talent training mode of architectural decoration engineering and technical expertise in the Pearl River Delta region should combine the economic characteristics of the region, making timely adjustments. This paper started from the background of current vocational education and the characteristics of the economy of the Pearl River Delta region, to analyze the impact of the regional economy on the training system of architectural decoration engineering and technical professionals, and put forward Suggestion on the training of architectural decoration engineering talents, suitable for the economic development of the Pearl River Delta.
\end{abstract}

Keywords: Architectural decoration engineering; Pearl River Delta; Economic development; Research

\section{建筑装饰工程技术专业适应 \\ 珠三角经济发展的研究}

\author{
魏爱敏 \\ (广州城建职业学院, 广东广州 510925 )
}

摘要: 经济发展, 教育先行。高职院校人才培养应满足区域经济发展的需要, 珠三角地区具有与其他区域明显不同的发 展特色, 珠三角地区的建筑装饰工程技术专业在人才的培养模式上要结合本地区的经济特色, 及时做出调整。本文首先从当 前职业教育的背景与珠三角地区经济的特点出发, 分析了本区域经济对建筑装饰工程技术专业人才培养体系的影响, 提出了 适应珠三角经济发展的建筑装饰工程技术专业人才培养的建议。

关键词: 建筑装饰工程技术; 珠三角; 经济发展; 研究

\section{1.研究背景与意义}

高等职业教育是我国高等教育的重要类型, 是高等教育体系中与经济发展联系最紧密的部分。目前我 国高等职业教育不管是招生规模还是在校生规模, 都已经占到了高等教育的半壁江山。高等职业教育在经 济和社会发展中的重要作用日益凸显, 《国家中长期教育改革和发展规划纲要(2010 - 2020 年)》明确提 出:“发展职业教育是推动经济发展、促进就业、改善民生、解决”三农'问题的重要途径, 是缓解劳动力供求 结构矛盾的关键环节，必须摆在更加突出的位置”。

《国务院关于加快发展现代职业教育的决定》（国发[2014]19 号）、《高等职业教育创新发展行动计 划（2015-2018 年）》（教职成[2015]9 号）、《教育部关于深化职业教育教学改革全面提高人才培养质量 的若干意见》（教职成[2015]6 号）等文件, 明确了各专业必须“服务区域经济发展, 明确人才培养定位”, 在深入开展社会调研的基础上, 充分了解产业转型升级与区域经济发展中出现的新特点和新变化, 进一步 
明确专业人才培养定位; 以职业分析为抓手, 以实践能力培养为重点, 努力使专业人才培养适应区域产业 发展和对技术技能人才的新需求，提升专业人才培养质量和水平。

当前我国正进入经济结构的战略调整时期，在《国民经济和社会发展第十三个五年规划纲要》中，推 行产教融合的职业教育模式。坚持面向市场、服务发展、促进就业的办学方向, 科学确定各层次各类型职 业教育培养目标, 创新技术技能人才培养模式。推行校企一体化育人, 推进“订单式”培养、工学交替培养, 积极推动校企联合招生、联合培养的现代学徒制。率先在大中型企业开展产教融合试点, 推动行业企业与 学校共建人才培养基地、技术创新基地、科技服务基地。鼓励学校、行业、企业、科研机构、社会组织等 组建职业教育集团, 实现教育链和产业链有机融合。建立健全对接产业发展中高端水平的职业教育教学标 准体系。以增强学生核心素养、技术技能水平和可持续发展能力为重点, 统筹规划课程与教材建设, 对接 最新行业、职业标准和岗位规范, 优化专业课程结构, 更新教学内容。强化课堂教学、实习、实训的融合, 普及推广项目教学、案例教学、情境教学等教学模式。完善职业学校教学工作诊断与改进制度。引导行业 企业深度参与专业教学、顶岗实习、岗位资格认证等方面的标准制定和教学评价。积极推行“双证书”制度, 统筹相关课程考试考核与职业技能鉴定。支持在符合条件的职业学校设立职业技能鉴定所（站），完善职 业学校合格毕业生取得相应职业资格证书的办法。规范职业学校办学行为, 严格落实专业教学标准, 防止 以升学为目标组织教学。

\section{2.珠三角地区经济发展现状对建筑装饰工程技术专业人才需求分析}

建筑装饰行业已经成为建筑业中的三大支柱性产业之一, 是一个劳动密集型行业。近些年来, 伴随中 国经济的快速增长以及相关行业的蓬勃发展, 建筑装饰行业愈加显示出了其巨大的发展潜力。据根中研 普华发布的《2014-2019 年中国建筑装饰行业发展前景预测与投资价值研究咨询报告》统计显示:我国建筑 装饰企业总数已达 48 万家左右, 直接从业人员高达 1660 万, 技术与管理人员的学历水平较之建筑施工技 术领域低, 行业内受过高等系统教育的人数占从业者总数的 $15 \%$ 左右, 许多建筑装饰企业的技术岗位有大 量的人才缺口。

2016 年, 广东建筑业生产经营保持低速平稳运行, 总承包和专业分包完成建筑业总产值 9652.31 亿元， 同比增长 $8.9 \%$, 增幅同比提高 2.8 个百分点, 比前三季度提高 1.1 个百分点。 2016 年, 装修装饰产值增长 较快,广东总承包和专业分包建筑业企业装修装饰产值 1407.85 亿元, 同比增长 $18.5 \%$, 增幅比上年提高 25.4 个百分点, 比前三季度提高 2.5 个百分点。增长较快的原因主要有: 一是房地产销售量快速增长, 带动建 筑业企业装修装饰产值; 二是年初工程合同充足, 工程比上年增多; 三是装修装饰经营转向精品装修工程, 高级人才人工成本和材料价格上升带动总产值上升。

我们学校建筑装饰工程技术专业的学生就业主要是面向珠三角, 因此本专业的人才培养一定要结合珠 三角的区域经济发展的特色和发展模式, 才能培养出适应工作岗位需要的实际能力, 适应产业转型升级和 企业技术创新需要, 培养产业转型升级与企业技术创新需要的发展型、复合型、创新型的技术技能人才。

通过对建筑装饰行业、企业对人才需求的分析可知，他们对建筑装饰工程技术专业的毕业 生的具体 要求是: 学生在毕业上岗时应能独立做出一套符合基本要求的装饰设计方案; 能正 确地领会和执行主管 设计师的设计意图和方案，并用电脑或手工绘制工程图、效果图; 能根据方案图绘制出设计图和平面、 立面、剖面施工图; 能进行建筑装饰工程管理及概预算; 熟悉建筑装饰工程的施工技能且能反馈工程实 
施过程中的技术问题并加以改进。笔者将企 业需求与我院学生的能力素质相比较, 认为学生毕业之前必 须加强如下几方面的专业能力才能得到用人单位的青睐:（1）具有较高的美学修养和艺术造型能力;

具有中小型方案图设计、施工图绘制能力和编制投标设计文本的能力; (3) 具有应用建筑装饰材料和管 理材料的能力; (4) 具有较强的中小型建筑装饰工程清单计量与计价能力、装饰工程预结算能力和应用 计算机软件编制装饰工程经济标的能力; (5) 具有较强的建筑装饰工程主要工种的操作能力和各分项工 程施工工艺技术能力; (6) 具有一定的建筑装饰工程项目施工组织方案设计和编制建筑装饰工程施工组 织投标文本的能力; (7) 具有较强的建筑装饰工程施工安全管理和质量检验的能力; (8) 具有熟练的工 程技术资料的收集与管理能力。

\section{3.建筑装饰工程技术专业适应珠三角区域经济发展的措施}

高职教育应以服务区域经济发展为目标，在为区域行业企业服务的过程中，应根据区域经济发展需要 及时调整自己的服务内容和手段, 使自身始终处于不断调整和变革中。以产教融合、校企合作为切入点, 创新“工学结合、知行合一”人才培养模式; 做实“专业定位与产业需求对接、课程内容与职业标准对接、教 学过程与生产过程对接、毕业证书与职业资格证书对接”, 优化课程体系、改革教学内容, 凝练专业特色, 培养适应产业转型升级和企业技术创新需要的高素质技术技能人才。

\section{1 构建适合珠三角地区经济发展的课程体系}

目前大多数的院校在课程设置上仍然沿用传统的建筑装饰工程技术专业课程体系, 以传授理论知识为 主。大一主要集中在公共课, 大二主要集中在理论课程, 学生在大三上学期开始将参加顶岗实习, 这种课 程体系直接导致学生在没有接受足够的实操训练后进人了企业。这样的培养体系, 不仅让学生的学习收获 不大, 更让他们很难适应企业的工作要求, 而企业也对高校培养的学生诸多不满。要改变这种现象首先应 从课程设置的结构改革出发, 按照围绕专业人才培养目标搭建 1 个校企协同育人平台, 把握专业定位与产 业需求、课程内容与职业标准、教学过程与生产过程、毕业证书与职业资格证书的 4 个对接, 实施知岗、 跟岗、模岗、顶岗的“4 岗”实践教学体系，把职业能力培养作为 1 条主线贯穿人才培养全过程的“1441”人 才培养思路，推进产教深度融合，创新“工学结合、知行合一”才培养模式。

根据职业素质与专业能力模块”、“基本素质与通用能力模块”及“公共基础学习领域、专业基础学习领 域、专业能力学习领域、专业拓展学习领域”的课程结构, 对接企业真实项目及生产过程, 贯穿培养学生 职业能力主线, 合理开发和设置课程, 形成工作过程导向的课程体系。按照专业核心技能竞赛项目进课堂 的要求, 课程体系中要明确列入相关职业资格考证及技能竞赛培训项目, 开发“课、证、赛”融合的课程群, 提高学生职业能力, 使我们的学生进人社会后, 不需要企业花费过多精力进行培训就能迅速适应工作岗位 的要求。

\section{2 加强与珠三角地区建筑装饰企业的纵深合作，提离学生实践能力}

在专业设置过程中, 缺乏企业的参与, 是我国职业教育发展比较明显的一个特征。虽然高职院校非常 注重学生的“实训”，加大了实训基地的建设力度，但是在校企合作方面，依然是“校热企冷”的尴尬局面。 因为学校通过校企合作，可以比较直观的了解就业市场对人力资源的需求状况，从而适当调整专业设置， 以便其与社会的需求动态适应。此外, 高职院校还可以借助企业的实习场地, 培养学生的职业素养与技能, 安置部分学生就业等。但是, 不少企业只关注于眼前的利益, 对参与校企合作的积极性始终不高。企业为 
了节约成本, 通常在招聘人才的时候又希望能够不培训或者少培训, 员工可以直接上岗。为突破这个瓶颈, 可采用与中小企业联盟或者行业协会联合培养的方式。在这个过程中，可以整合各企业的优势资源，为建 筑装饰工程技术专业学生提供大量实习机会, 锻炼他们的实际操作能力以便迅速的适应企业环境。同时, 通过成立专业指导委员会, 将区域中的一些骨干企业的带头人或者行业协会的主要负责人聘请为校专业指 导委员会的委员, 这不仅可以加强与企业的沟通, 迅速掌握企业对人才需求的变动, 使学校的人才培养能 结合企业真实需求，同时还可以聘请专业指导委员会的成员作为校外兼职教师，充实专业的教师内涵，使 专业课教师分布更趋于合理。

\section{3 实施课证结合培养方式}

构建适应新时代下技能竞赛的教学评价机制。改革现有职业教育评价体系，建立等级评价指标体系， 完善职业教育评价体系, 促进职业教育健康持续地发展。打破理论学习型的评价体系, 建立能力应用型的 “课、岗、证、赛”融合的评价体系。以职业技能竞赛指导思想优化人才培养目标, 在专业教学计划中明确 列入相关职业资格考证项目及 “课、岗、证、赛”融合的课程群。以培养学生职业能力为主线, 合理整合课 程, 优化课程体系。

着力提升建筑装饰工程技术专业的人才培养质量, 加强本专业学生的职业精神培育, 推进产业文化、 优秀企业文化、职业文化进校园进课堂，促进职业技能和职业精神高度融合，着力培养建筑装饰工程技术 专业的学生崇尚劳动、敬业守信、精益求精、敢于创新的工匠精神。推动职业学校与行业企业共建建筑装 饰技能大师工作室、校企合作研发中心等, 完善本专业学生技能竞赛制度。

\section{4.结论及建议}

\section{1 专业的设置以市场需求为导向}

专业设置与区域经济的发展紧密联系，在专业设置上既充分立足于当今的市场需求，又积极为未来的 劳动力市场需求全面规划, 从而保障专业设置有了一定的市场适应性和前瞻发展性。珠三角地区的建筑装 饰工程技术专业, 高职院校应依据本地区的经济发展和企业生产部门的用工需求有针对性地设置专业, 其 专业设置突出应用型为主。在对劳动力市场充分调研分析之后, 有针对性的开设专业, 并使开设专业的人 才培养符合本地区企业的用工需求。

\section{2 以“校企合作”为办学形式}

高职教育人才培养目标和定位要十分清晰, 就是为区域经济发展培养产业转型升级与企业技术创新需 要的发展型、复合型、创新型的技术技能人才。为了实现这一人才培养目标, 高职院校的专业设置上要求 是由企业直接参与、高职院校共同制定形成的。高职院校的每一个专业都相应的成立专业建设指导委员会, 其成员由企业及学院的相关代表组成, 负责制定本专业的教学计划、课程的实施、实习实训的安排等方面。 校企协同系统设计专业实践教学内容，按照基本技术技能、专业技术技能和综合技术技能应用能力层次， 循序渐进地安排实践教学内容。毕业实践教学环节要对接企业真实项目开展顶岗实习和毕业设计, 重点推 行基于工作问题、工作项目、工作案例和工作过程导向的教学模式和学习方法，加强生产性、综合性实践 项目设计和应用, 提高学生专业技术技能水平。因此, 培养的学生有很强的岗位针对性, 让学生学以致用, 毕业之后就可以直接适应就业岗位的需求。 


\section{3 加强专业群建设}

在经济发展过程中，区域产业结构的不断调整及优化升级，依据与产业发展的关联程度，高职院校必 须加强专业群建设, 形成自身的专业集群优势, 合理谋划高职院校专业集群的发展目标和方向, 以更实际 的行动服务区域经济建设。

现代职教体系的发展对专业的需求是专业集群发展的内在动力源。高职院校在专业集群的建设思路 上, 可以根据高职院校现有的专业为基础, 以已经形成的优势专业、特色专业、品牌专业作为龙头专业, 将现有的其它有关联的专业按照专业集群建设的目标进行优势资源组合。专业集群的重点建设专业具有办 学特色鲜明、师资力量雄厚、实习实训设备先进、校企合作紧密、毕业生就业率高等特点。

高职院校是直接面向区域经济建设服务的，反过来区域经济产业的发展又为高职院校的相关专业发展 起到了“风向标”的指示作用，区域产业的发展是职业教育发展的基石，职业教育培养的技能型人才又为区 域产业的发展与繁荣服务，从一定角度上来说，区域产业集群与高职院校是相互依存、相互补充、相互促 进、共同发展的关系。找准学院自身所处区域产业集群的发展优势, 准确把握区域产业发展的前景、趋势 以及特色, 是高职院校在专业设置中的首要任务。高职院校培养的技能型人才是为区域经济建设而服务的, 一方面是区域经济发展的需要，另一方面也体现了职业教育“以服务为导向”的办学理念。

\section{5.致谢}

本文系国家留学基金委“2016 年高等教育教学法出国研修项目”（项目编号：留金发 [2016］5054）资 助, 广州城建职业学院 2016-2017 学年立项重点课题 “建筑装饰工程技术专业适应珠三角经济发展的研 究” 的研究成果之一。(课题编号: Z201601)

\section{Acknowledge}

This article is supported by the National Study Abroad Fund "2016 Higher Education Teaching Law to study abroad project" (project number: stay blonde [2016] 5054), one of the research results of Guangzhou Urban Construction Vocational College 2016-2017 Academic Year key project "architectural decoration engineering technology to adapt to the Pearl River Delta Economic development research ". (Project number: Z201601)

\section{参考文献:}

[1]佟艳芬.区域经济一体化视域下的高职专业设置研究——以广东省为例[J].吉林省教育学院学报,2017,(02):114-116.

[2]刘琦.珠三角地域经济发展现状对国贸人才培养的影响分析[J].佳木斯职业学院学报,2016,(10):445-446.

[3]王红梅.基于区域经济发展特点的现代学徒制专业教学标准研究——以东科学技术职业学院应用电子技术专业为例 [J].黑龙江教育学院学报,2016,(07):45-47.

[4]陈基纯.珠三角地区高职院校专业设置与区域经济发展吻合度研究[J].职业技术教育,2015,(05):8-13.

[5]刘旭平.高等职业教育专业设置与区域经济协调发展研究[J].教育与职业,2014,(21):12-14.

[6]左超.高职院校专业设置与区域经济协调发展研究[D].广东技术师范学院,2012.

[7]张龙.高职教育专业设置与建设适应区域经济发展的理性思考[J].教育与职业,2010,(35):11-13.

[8]包红霞.高职专业设置与区域经济发展适应性研究[J].教育与职业,2010,(23):41-42.

[9]黄乐览,黄伟萍.适应珠三角经济发展的高职人才培养模式探讨[J].中国职业技术教育,2010,(15):20-22.

[10]宋小杰,曹晔.广东省高职院校专业设置与区域经济发展的适应性研究[J].河南科技学院学报,2010,(04):7-11. 
[11]胡林.打造适应泛珠三角经济区域发展需要的会展管理新专业[J].江西行政学院学报,2006,(S2):84-87.

[12]李顺华. 高职建筑装饰工程技术专业人才需强化的能力探析[J]. 艺术科技,2013,(09):29+33.

地址: 广州从化环市东路 166 号广州城建职业学院建筑工程学院 魏爱敏收

电话: 13925119162

作者简介:

魏爱敏, 女, 生于 1977 年, 广东人, 讲师, 工艺美术师, 主要研究方向为建筑经济及高职教学管理。

\section{References}

[1] Tong Yan-fen. Study on the Specialty Setting in Higher Vocational Education from the Perspective of Regional Economic Integration - Taking Guangdong Province as an Example [J]. Journal of Jilin Province Education College, 2017, (02): 114-116.

[2] Liu Qi. Analysis on the impact of Pearl River Delta regional economic development status on international trade personnel training [J]. Journal of Jiamusi Vocational College, 2016, (10): 445-446

[3] Wang Hongmei. Study on the Teaching Standard of Modern Apprenticeship Based on the Characteristics of Regional Economic Development - Taking the Application of Electronic Technology Specialty in Guangdong University of Science and Technology as an Example [J]. Journal of Heilongjiang College of Education, 2016 (07): 45-47

[4] Chen Jichun. Vocational and Technical Education, 2015, (05): 8-13 (in Chinese with English abstract). [J]. Vocational and Technical Education, 2015, (05): 8-13. [J]. Vocational and Technical Education, 2015, (05): 8-13.

[5] Liu Xuping. Study on the professional development of higher vocational education and the coordinated development of regional economy [J]. Education and Occupation, 2014, (21): $12-14$.

[6] Zuo Chao. Professional development of vocational colleges and regional economic coordinated development [D] .Guangdong Technical Teachers College, 2012.

[7] Zhang Long. Higher vocational education and set up to adapt to the regional economic development of rational thinking [J]. Education and occupation, 2010, (35): 11-13.

[8] Bao Hongxia. Professional development and adaptability of regional economic development [J]. Education and Occupation, 2010, (23): 41-42.

[9] Huang Lelan, Huang Weiping. Chinese Vocational and Technical Education, 2010, (15): 20-22. [J]. Chinese Vocational and Technical Education, 2010, (15): 20-22. [9] Huang Leming, Huang Weiping.

[10] Song Xiaojie, Cao Ye. Study on the Adaptability of Professional Setting and Regional Economic Development in Higher Vocational Colleges in Guangdong Province [J]. Journal of Henan Institute of Science and Technology, 2010, (04): 7-11. [J];

[11] Hu Lin. To create a new professional exhibition management for the development of the Pan-Pearl River Delta economic region [J]. Journal of Jiangxi Administration Institute, 2006, (S2): 84-87.

[12] Li Shunhua. Higher vocational building decoration engineering and technical professionals 
need to strengthen the ability of [J]. Art Technology, 2013, (09): 29-33.

Address: Guangzhou Conghua Road, No. 166, Guangzhou City Construction Vocational College of Architectural Engineering, Wei Aimin received

Tel: 13925119162

Address: School of Architectural Engineering of GZCCC, No. 166, East Huanshi Road, Conghua, Guangzhou, Recipient: WEI Aimin

Telephone: 13925119162

\section{Introduction to the author:}

Aimin Wei, female, born in 1977, from Guangdong Province, lecturer, craft artist, main research direction: Construction Economy and Higher Vocational Teaching Management 